\title{
MACROECONOMIC ASPECTS OF COMPETITIVENESS
}

\author{
Oleg HOOKE ${ }^{1}$ \\ State Research Institute of Informatization and Economic Modeling, Ukraine
}

\begin{abstract}
In the process of globalization of world economic processes, the role of individual national economies increases, comparative advantages of the development of a country are formed, and their competitiveness is ensured. That is why it is worth emphasizing the importance of increasing the competitiveness of each individual country, based on its internal capacity. In a broad aspect, the competitiveness of the national economy is perceived as the ability of the country to ensure the balance of its external proportions and to avoid those constraints imposed by the foreign economic sphere, to self-organizing the improvement of their world economic ties. The competitiveness of the economy at the macro level is associated with the duration of the cycle of reproduction of the main productive assets and, accordingly, the jobs, productive forces of society and determined by the overall economic efficiency of investment. The criteria of competitiveness of the national economy are the growth of social productivity of labor, increase of social and economic efficiency of production and standard of living of the population. The competitiveness of the national economy determines sustainable socio-economic development of the country, as well as sustainable development predetermines the competitiveness of not only the country, but also all its levels. Scientific results are obtained using special methods of research of economic objects and phenomena, that is, based on the correlation and regressive, comparative analysis (establishing the relationship between the indicator factor), as well as economic modeling. Findings. Generalizing analysis and the importance of the macroeconomic aspect of competitiveness were used in the research paper, which will allow to better respond to the economic situation, in accordance with the trends of the "green" transformation of the economy; which in turn will solve important problems of the development and implementation of its economic development strategy based on the principles of sustainable development and, accordingly, with the trends of the "green" transformation of the economy. The practical significance of this research paper is that the resulting conclusion and generalizations will help the state, regional government, local self-government, as well as enterprises, solve important problems of developing and implementing their economic development strategies based on the principles of sustainable development and, accordingly, along with the trends of the "green" transformation of the economy. Value. In terms of a crisis of competitiveness, the advantages are primarily obtained not through improving the quality of products, but through reducing costs. Thus, one of the goals of the Ukrainian economy at the present stage is to become competitive and maximize the usage of its macroeconomic aspect.
\end{abstract}

Key words: competitive advantages, theoretical approaches and concepts of competitiveness, linking competitiveness with "sustainable development", the essence of "sustainable development", structural components of sustainable development.

JEL Classification: E6, D41, E37, O11, O16, O2

\section{1. Введение}

Стоит отметить, что основательный анализ экономики страны напрямую зависит от обоснования и исследования ее конкурентоспособности, с ее актуальными концептуальными подходами, что связано с воспроизведением производительных сил общества, а также укучшением своих мирохозяйственных связей. ВеАь Аостижение конкурентоспособной экономики в контексте устойчивого развития может опредемяться возможностью государства обеспечивать равные условия Аля стимулирования развития национального

Corresponding author:

${ }^{1}$ State Research Institute of Informatization and Economic Modeling.

E-mail: olegguk1975@ukr.net производства и экспорта, содействие экономической и преАпринимательской активности с интенсивным применением инновационных решений и одновременно подАерживать и повышать в течение Алительного времени реальные Аоходы населения, стимулировать социальное развитие общества, включая подАержку образования, зАравоохранения, и обеспечивать максимальную энергоэфективность и экологичность в реальном секторе экономики и обществе.

Наиболее весомых результатов в конкурентоспособности экономики страны можно Аостичь, разви- 
вая ее на принципах устойчивого развития. Экономическая, социальная и экологическая составляющие устойчивого развития являются приоритетами развития экономик веАущих стран мира. Аля Украины, которая активно взяла курс на евроинтеграцию является крайне важным, чтобы национальная украинская продукция была экологической и удовлетворяла бы требования на европейских рынках. Поэтому сегодня вопрос повышения конкурентоспособности экономики Украины на принципах устойчивого развития стоит достаточно остро переА государственными органами, Украинскими товаропроизводитемями и институтами гражАанского общества.

Поэтому ијелью Аанной статьи явмяется определение макроэкономического аспекта конкурентоспособности, ее значение Амя экономики страны. Это в свою очередь будет способствовать реацизации усмовий Аля оптимального сочетания процессов повышения конкурентоспособности и обеспечения устойчивого развития.

\section{2. Экономическая сущность понятия конкурентоспособность}

В общем виде конкурентоспособность независимо от уровня управления - это внутреннее свойство субъекта, которое проявцяется только в ходе конкуренции, в процессе рыночных отношений, управляемое со стороны самого субъекта конкуренции; оно характеризуется большей степенью удовлетворения потребностей покупатемей по сравнению с аналогичными объектами, представленными на данном рынке, и определяется конкурентными преимуществами в размичных областях деятельности субъекта по отношению к конкурентам, что в совокупности позвоцяет не только удовлетворять потребности населения и производства, но и товаропроизводителя, осуществлять расширенное воспроизводство в условиях конкуренции (Kudashov, Holovachev, 2012).

Синтезирующим показателем, объединяющим конкурентоспособность товаров, товаропроизвоАителей (микроуровень), отраслей (мезоуровень) характеризующий состояние страны на мировом рынке (макроуровень) явмяется конкурентоспособность национальной экономики. Экономическая категория «конкурентоспособность национацьной экономики» вошла в экономического оборота в 80-х годах XX века, в связи с обострением конкуренции межАу странами, хотя существовали и более ранние упоминания этого термина.

\section{3. Генезис понятия конкурентоспособность}

Следует отметить, что начало XXI века ознаменовалось появлением многих новых теоретических поАХодов к опреАелению конкурентоспособности национальной экономики: инновационно-инфор- мационной парадигмы глобальной конкурентоспособности; теории стадий экономического развития национальных экономик в зависимости от характера и источников экономического развития, теории глобального опережение конкурентов и уникальной ценности, инновационного подхода, направценного на инвестиции в человеческий капитал, а также в инфраструктуру и прикладные НАПКР, интегрального ПоАХоАа, социально-институционального поАхода (В Украине после 4 мет падения выросло промышиенное производство - госстат, 2015) и Аругие.

С целью основательного анализа экономики страны, а точнее ее конкурентоспособности актуамьны следующие подходы: факторный, изучающий Аинамику роста экономики нации (а это является основой Авижения позиций нашей страны на всех мировых рынках) ресурсный (имеется в виду оценка технологий, наличие или отсутствие капитала, который может быть использован Аля инвестирования, изучение как квалификации, так и численности человеческих ресурсов, природных ресурсов и, несомненно, экономико-географическое положение Украины); рейтинговый, то есть определения состояния экономики в интеграцьном отображении, используя определенную систему показателей. В ^юбом случае такая система показателей конкурентоспособности государства включает в себя еще и отличительные особенности элементов народнохозяйственного механизма. Но самое главное, что в системе показателей исследуется и внешнеэкономическая составмяющая. Именно этим определяется ведущая цель такой деятельности.

В широком аспекте конкурентоспособность национальной экономики воспринимается как способность страны обеспечивать сбалансированность своих внешних пропорций и избегать тех ограничений, которые обусловливаются внешнеэкономической сферой. Конкурентоспособность экономики на макроуровне связана с продолжительностью цикла воспроизводства основных производственных фонАов и соответственно рабочих мест, производительных сил общества и определяется общехозяйственной эффективности капиталовложений (Богиня, Шевченко, 2008).

Вместе с развитием теории межАународной конкурентоспособности определение этого термина заметно модифицировались в направлении усложнения и расширения охвата факторов, влияющих на конкурентоспособность экономики. Необходимо отметить, что, несмотря на широкое использование понятия «конкурентоспособности экономики страны», среди научных исследований до сих пор не существует ни одного четкого определения этого термина. Не только отечественные, но и зарубежные ученые обращают внимание на элементы Аанной категории (в Аиапазоне от технологических к общему общественно-политических). 
Таблица 1

\section{Трактовки понятия «конкурентоспособность национахьной экономики»}

\begin{tabular}{|c|c|}
\hline Автор & Трактовки, характеристика по источнику \\
\hline $\begin{array}{l}\text { Президентская Комиссия } \\
\text { по Аелам конкурентоспо- } \\
\text { собности американской } \\
\text { промышиенности }\end{array}$ & $\begin{array}{l}\text { состояние экономики, когАа страна в условиях свободного и честного рынка может производить товары } \\
\text { (услуги), которые соотносятся с требованиями международного рынка, и в то же время сохранять или } \\
\text { повысить реальные доходы своих гражАан }\end{array}$ \\
\hline $\begin{array}{l}\text { World Competitiveness } \\
\text { Report (1994 p.) }\end{array}$ & $\begin{array}{l}\text { является результатом преобразования ресурсов страны, то существующих (например, природные ресурсы), } \\
\text { или созданных (инфраструктура, человеческий капитал) благодаря производственным процессам в экономи- } \\
\text { ческие результаты, которые затем проверяются средствами конкуренции на международных рынках }\end{array}$ \\
\hline OECD (1996) & $\begin{array}{l}\text { способность компаний, отраслей, регионов, наций и наднациональных пространств созАавать сравни- } \\
\text { тельно высокий уровень доходов и уровень занятости на устойчивой основе, оставаясь открытыми Аля } \\
\text { международной конкуренции }\end{array}$ \\
\hline $\begin{array}{l}\text { World Competitiveness } \\
\text { Yearbook (2011 p.) }\end{array}$ & $\begin{array}{l}\text { пространство экономических знаний, который анализирует факты и политику, формируя способность } \\
\text { страны к созданию и сохранению окружения, способствует созАанию большей ценности ААя преАприя- } \\
\text { тий и благосостояния }\end{array}$ \\
\hline $\begin{array}{l}\text { World Economic forum } \\
\text { (2009) }\end{array}$ & $\begin{array}{l}\text { набор институтов, политики, факторов, определяющих уровень производительности факторов про- } \\
\text { изводства в стране. КАючевым здесь является влияние на экономическую Аинамику в Аолгосрочном } \\
\text { периоде обеспечивает стране защиту от нежелательных последствий экономических колебаний }\end{array}$ \\
\hline $\begin{array}{l}\text { Закон Украины } \\
\text { «О защите экономиче- } \\
\text { ской конкуренции» }\end{array}$ & $\begin{array}{l}\text { соревнования между субъектами хозяйствования за получение преимуществ переА Аругими субъектами } \\
\text { хозяйствования, вследствие чего потребители (субъекты хозяйствования) имеют возможность выбирать } \\
\text { между несколькими продавцами, а отдельный субъект хозяйствования не может определять условия } \\
\text { обращения товаров на рынке }\end{array}$ \\
\hline Б.В. Губский & $\begin{array}{l}\text { обусловлено экономическими, социальными и политическими факторами устойчивое положение } \\
\text { страны на внутреннем и внешнем рынках, способность субъектов конкурентной борьбы противостоять } \\
\text { международной конкуренции на внутреннем рынке и рынках других стран }\end{array}$ \\
\hline Я.Б. Базилюк & $\begin{array}{l}\text { характеризует состояние общественных отношений в государстве по формированию и реализации } \\
\text { экономической политики, Амя обеспечения условий стабильного повышения эффективности националь- } \\
\text { ного производства, адаптированного к изменениям мировой конъюнктуры и растущего спроса населе- } \\
\text { ния на основе достижения мучших, чем у конкурентов, социально-экономических параметров. }\end{array}$ \\
\hline Я.А. Жалимо & $\begin{array}{l}\text { способность экономической системы обеспечивать социально-экономическую оптимальность Аюбого } \\
\text { влияния и внешних факторов }\end{array}$ \\
\hline $\begin{array}{l}\text { А. Гальчинский, В. Геец, } \\
\text { А. Кинах, } \\
\text { В. Семиноженко }\end{array}$ & $\begin{array}{l}\text { способность производить и потреблять товары и услуги в условиях конкуренции с товарами и услугами, } \\
\text { производимыми в Аругих странах, при этом результатом конкуренции должен быть рост жизненного } \\
\text { уровня населения при соблюдении межАународных экологических стандартов }\end{array}$ \\
\hline А.А. Антонюк & $\begin{array}{l}\text { способность страны занимать и удерживать устойчивые позиции на определенных сегментах мирового } \\
\text { рынка благодаря мощному экономическому потенциалу, что обеспечивает рост экономики на иннова- } \\
\text { ционной основе; развитой системе рыночных институтов; владении значительным интелмектуальным } \\
\text { капиталом, инвестиционными ресурсами; гибким реагированием на изменения мировой конъюнктуры и, } \\
\text { соответственно этому, диверсификацией производства, максимально отстаивая реализацию национальных } \\
\text { интересов ради экономической безопасности и высоких стандартов жизни населения }\end{array}$ \\
\hline С.В. Мочерный & $\begin{array}{l}\text { способность экономики Аанного государства конкурировать с экономиками Аругих стран по уровню } \\
\text { эффективного использования национальных ресурсов, повышения производительности народного } \\
\text { хозяйства и обеспечение на этой основе высокого и постоянно растущего уровня жизни населения синтез } \\
\text { качества и возможности успешной реализации продукции на конкурентном отечественном или междуна- } \\
\text { родном рынке в определенный момент времени за счет достижения конкурентных преимуществ }\end{array}$ \\
\hline Т.В. Гринько & $\begin{array}{l}\text { синтез качества и возможности успешной реализации продукции на конкурентном отечественном или } \\
\text { международном рынке в определенный момент времени за счет достижения конкурентных преимуществ }\end{array}$ \\
\hline Р.А. ФатхутАинов & $\begin{array}{l}\text { свойство объекта, характеризующее степень реального ими потенциального удовлетворения им конкретной } \\
\text { потребности по сравнению с аналогичными объектами, представленными на конкретном рынке }\end{array}$ \\
\hline $\begin{array}{l}\text { О.С. Богма, } \\
\text { О.В. Болдуева }\end{array}$ & $\begin{array}{l}\text { способность страны в условиях социально ориентированной национальной экономики обеспечивать высо- } \\
\text { кое качество жизни нации на основе эффективного использования национальных ресурсов и эффективной } \\
\text { системы производства товаров и услуг, отвечающих установленным международным стандартам }\end{array}$ \\
\hline Аж. Сакс & $\begin{array}{l}\text { определяется наличием в стране зАорового рынка факторов производства и Аругих характеристик, которые } \\
\text { формируют потенциал Амя достижения стабильного экономического роста. ЗАоровая экономика Аолжна } \\
\text { быть подкреплена ростом Аеловой активности, управмяемая законом и стабильно работающими рынками }\end{array}$ \\
\hline А. Аолар и Е. Вульф & $\begin{array}{l}\text { сочетание Аостижения успеха в международной торговле на базе высокой технологии и производитель- } \\
\text { ности с высокими доходами и заработной платой }\end{array}$ \\
\hline М. Аанн & $\begin{array}{l}\text { гибкость, с которой национальная экономика способна предвидеть структурные изменения и адаптиро- } \\
\text { ваться к ним. Важнейшим признаком конкурентоспособности является ее изменение во времени. }\end{array}$ \\
\hline М. Портер & производительность - основной элемент межАународной конкурентоспособности на национальном уровне \\
\hline Б. Скотт, Аж. АоАЖ & $\begin{array}{l}\text { способность экономики к производству, распредемению товаров и предоставмения посмепродажных } \\
\text { услуг Аля межАународного бизнеса ... таким образом, чтобы достичь большего уровня }\end{array}$ \\
\hline
\end{tabular}

Источник: сформирована автором на основе (Kudashov, Holovachev, 2012, Bohma, Boldueva 2010; Poluneev, 2008 
В таблице 1 приведено сравнение существующих признаков и трактовок категории «конкурентоспособности национацьной экономики» с экономической точки зрения.

Как виАим, большое количество экономистов тяготеют к опреАелению этого понятия, как способность совершенствовать и производить услуги и изделия высокого сорта или меньшей стоимости, чем анамогичные у Аругих производителей. Следующие же тяготеют к определению «конкурентоспособности» в связи с согласованностью экономических структур и разАичных институтов государства с экономическим ростом, не выходя за рамки организации экономики мира в целом; экономика может считаться способной к конкуренции при условии, что вышеупомянутые институты страны и ее политика гарантируют продуктивное роста экономики.

\section{4. Концепции конкурентоспособности}

Исследуя вопрос конкуренции, можно выделить следующие основные концепции конкурентоспособности национальной экономики:

- способность страны продавать, повышать производительность, приспосабливаться к изменениям и внеАрять инновации, привлекать инвестиции и человеческий капитах (Denysov, Nazareva, Gryshchenko, 2016).

- возможность продавать (экспортировать), привлекать ресурсы, приспосабливаться к изменениям внешней среды и получать доход (зарабатывать). На основе этих факторов выстраивается иерархия конкурентоспособности, в основе которой межат три первых указанных фактора, а переход к четвертой стадии конкурентоспособности происходит бцагодаря накоплению знаний (Okruzhajushhaja sereda Ukrainy za 2014 god, 2015).

- соответствие трем условиям: продается (экспортируется) достаточный объем товаров и услуг; аккумулированный прибыль от использования факторов производства, который по меньшей мере оправАывает вложенные среАства и соответствует норме рентабельности в странах с похожим уровнем экономического развития; гражАане Аовольны макроэкономическими условиями;

- конкурентоспособность страны на мировых рынках (глобальная, национальная, международная), которая обусловлена стратегией захвата мировых рынков и зависит от внешнеэкономической Аеятельности государства. ОтАельные исследователи придерживаются мнения, что макроэкономическая национальная конкурентоспособность со временем будет вытесняться конкурентоспособностью отАельных преАприятий (масштабность, глобальность действий ТНК);

- конкурентоспособность национальных преАприятий как на внутреннем, так и мировом рынках.
В этом случае конкурентоспособность экономики государства будет зависеть от позиции на рынке определенных национальных компаний и экономического потенциама страны.

Критериями конкурентоспособности национамьной экономики явмяется рост общественной производительности труАа, повышение социальной и экономической эффективности производства и уровня жизни насемения. Конкурентоспособность национацьной экономики обусловливает устойчивое социально-экономическое развитие страны, так же как устойчивое развитие преАопреАеляет конкурентоспособность не только страны, но и всех ее уровней (Bohma, Boldueva, 2010). Потенциал роста по всей стране может быть повышен за счет увеличения местной и региональной конкурентоспособности и создания более благоприятного климата Аля развития преАпринимательства, инноваций и инвестиций. Общие экономические показатели страны измеряются с точки зрения ее способности обеспечивать своих гражАан растущим уровнем жизни на устойчивой основе и широкий Аоступ рабочих мест Амя тех, кто желает работать. Конкурентоспособность означает устойчивый рост уровня жизни народа или региона, а также низкий уровень безработицы.

\section{5. Конкурентоспособность в контексте устойчивого развития}

ОчевиАно, что глобализация, экономический и социальный прогресс, устойчивость и конкурентоспособность развиваются параммельно и оказывают существенное влияние Аруг на Аруга. Конкурентоспособность Аолжна основываться на широком видении экономики и общества. В современных условиях возникает необходимость в проведении исслеАования по разработке новой концепции «стойка конкурентоспособность», или «конкурентоспособность в контексте устойчивого развития в в условиях глобализации, причем большая часть исследований, направленных как на устойчивое развитие, так и на конкурентоспособность, Аолжны взаимодействовать. Такие Аополнительные исследования приведут К появцению новых теоретических моделей и опреАелять их макроэкономический аспект, описывать отношения межАу меЖАунароАной гмобализацией, экономическим ростом, устойчивым развитием, благополучием и конкурентоспособностью.

Сущность «устойчивого развития» заключается в максимизации экономических и социальных дохоАов от процесса развития системы национального хозяйства, при условии защиты окружающей среАы и обеспечения в Аолгосрочной перспективе воспроизводства природных ресурсов. В экономическом смысле устойчивое развитие означает не только рост национацьной экономики и увеличение АохоАов на Аушу насемения, но и укучшения всех элемен- 
тов социального обеспечения. Устойчивое развитие Аолжно сопровожАаться необходимыми структурными изменениями в экономической и социальной сферах. Сущность концепции устойчивого социально-экономического развития заключается в удовлетворении реальных потребностей человека без созАания угрозы удовметворения потребностей будущих поколений. Устойчивое социально-экономическое развитие означает реализацию трех взаимосвязанных и взаимообусловленных целей: создание более конкурентоспособной, высокоэффективной и низкозатратной экономики; повышение жизненного уровня населения; улучшение экологической обстановки. Схематично устойчивое развитие преАстав$\Lambda$ ено на рис. 1.

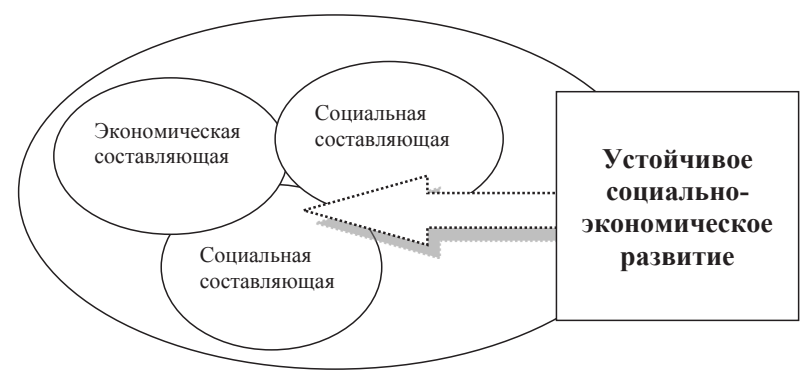

Рис. 1. Структурные составмяющие устойчивого развития

Источник: составлено автором по данным (Poluneеv, 2008)

Стало очевидно, что экономическое благополучие, Аостигнутое за счет Аеградации окружающей среды, угрожает существованию человека как биологического вида, его физическом и психологическом зАоровью, и особенно зАоровью буАущих покомений. В этой ситуации у человека есть еАинственный выход - найти устойчивое равновесие между экономическим благополучием и сохранением благополучной Амя него среАы и выйти на траекторию устойчивого развития. Итак, конкурентоспособность национальной экономики воспринимается как способность страны обеспечивать сбалансированность своих внешних пропорций и избегать тех ограничений, которые обусловливаются внешнеэкономической сферой, обновмением и улучшениемсвоих мирохозяйственных связей. Макроэкономический аспект конкурентоспособности проявляется в процессе конкуренции межАу размичными факторами, опреАемяет преимущества товаров, отраслей, территорий, государств относительно конкурентов и формирует возможность кучшего уАовлетворения потребностей и интересов потребителей и способствует расширенному воспроизводству производства.

\section{6. ВЫвоАЫ из Аанного исслеАования и перспективы}

Вопросы устойчивого развития Аолжны как никогАа стать главными вопросами современной экономической науки, поскольку реальное Аостижение Аостойной жизни, решение стратегических проблем развития регионов и зон, в том числе и достижения продовольственной безопасности страны, становится невозможным. Без такого подхода тенденцию обеспечения устойчивого развития страны и ее регионов можно завести в тупик, и на повестке Аня рано или позАно встанет вопрос разработки теоретических и методологических основ обеспечения устойчивого развития всего хозяйственного комплекса страны (Poluneev, 2008).

\section{References:}

Kudashov, V.I. Holovachev, A.S. (2012). Konkurentosposobnost' jekonomiki: innovacionnyj podhod: monografija. Minsk: Izd-vo MIU, 484.

In Ukraine, after 4 years of Decline, Industrial Production Has Grown - State Statistics. Available at: http:// www.5.ua/ekonomika/v-ukraini-pislia-4-rokiv-padinnia-zroslo-promyslove-vyrobnytstvo-136640.html

Bohynia, D., Shevchenko, A. (2008). Jefektivnost' truda v rynochnoj jekonomike. Ukraina: aspekty truda, 4, 3-6.

Fedulova,L. (2006). Perspektivy innovacionnogo razvitija promyshlennosti Ukrainy.Jekonomika i prognozirovanie, $5,58-76$.

Herasymchuk, Z.V. (2001). Regional'naja politika stalogo razvitija: metodologija formirovanie, mehanizmy realizacii. NAN Ukrainy; Institut regional'nyh issledovanij. Luck : Nadstir'ja, 528.

Denysov, V.T., Nazareva, N.A. Gryshchenko, O.V. (2016). Adaptivnoe upravlenie - osnova uspeha dejatel'nosti promyshlennogo predprijatija. Vesnik OGU, №8, 89-95.

Okruzhajushhaja sereda Ukrainy za 2014 god. (2015). Ctatisticheskij sbornik Gossluzhbi statistiki Ukrainy. Kiev, 223.

Bohma, O.S., Boldueva O.V. (2010). Rol' innovacij v obespechenija konkurentosposobnosti nacional'noj jekonomike. Vesnik Zaporozhskogo nacional'nogo universiteta. Jekonomicheskie nauki, № 3, 166-170.

Poluneev, Ye.V. (2008). Tehnologija jekonomicheskogo proryva: konkurentosposobnost' strany i opredelenie strategicheskih prioritetov. Demografija i social'naja jekonomika, №2 (10), 29-41. 


\section{Олег ГУк}

\section{МАКРОЭКОНОМИЧЕСКИЙ АСПЕКТ КОНКУРЕНТОСПОСОБНОСТИ}

Аннотация. В процессе глобализации мировых экономических процессов повышается роль отдельных национальных экономик, формируются сравнительные преимущества развития той или иной страны, обеспечивается их конкурентоспособность. Именно поэтому стоит подчеркнуть важность повышения конкурентоспособности каждой отдельнойстраны, исходяизвнутреннегоеепотенциала.Вширокомаспекте конкурентоспособность национальной экономики воспринимается как способность страны обеспечивать сбалансированность своих внешних пропорций и избегать тех ограничений, которые обусловливаются внешнеэкономической сферой, самоорганизовывать улучшения своих мирохозяйственных связей. Конкурентоспособность экономики на макроуровне связана с продолжительностью цикла воспроизводства основных производственных фондов и соответственно рабочих мест, производительных сил общества и определяется общехозяйственной эффективности капиталовложений. Критериями конкурентоспособности национальной экономики является рост общественной производительности труда, повышение социальной и экономической эффективности производства и уровня жизни населения. Конкурентоспособность национальной экономики обусловливает устойчивое социально-экономическое развитие страны, так же как устойчивое развитие предопределяет конкурентоспособность не только страны, но и всех ее уровней. Научные результаты получены с использованием специальных методов исследования экономических объектов и явлений, то есть основываясь на основе корреляционнорегрессивного, сравнительного анализа (устанавливая взаимосвязь между факторами-показателями), а также экономического моделирования. Результаты. В статье использован обобщающий анализ и значение макроэкономического аспекта конкурентоспособности, который позволит лучше реагировать на экономическую ситуацию, в соответствии с тенденциями «зеленой» трансформации экономики; что позволит в свою очередь решить важные проблемы разработки и реализации своей стратегии экономического развития на принципах устойчивого развития и, соответственно, с тенденциями «зеленой» трансформации экономики. Практическое значение изложенного в статьи заключается в том, что полученный вывод и обобщения в ней послужит государственным, региональным органам управления, местному самоуправлению, а также предприятиям, решать важные проблемы разработки и реализации своей стратегии экономического развития на принципах и принципах устойчивого развития и, соответственно, с тенденциями «зеленой» трансформации экономики. Значение. В условиях кризиса конкурентоспособности преимущества прежде всего добываются не повышением качества продукции, а сокращением расходов. Таким образом одной из целей украинской экономики на современном этапе - это стать конкурентоспособной и использовать по максимуму ее макроэкономический аспект. 